\title{
GIANT LYMPHANGIOMA OF THE BREAST IN AN ADULT
}

\author{
Suresh R. Harbade, Pravinkumar P. Wasadikar, Anagha S. Varudkar.
}

1. Assistant professor, Department of Surgery, Government Medical College, Aurangabad(MS)

2. Associate Professor, Department of Surgery, Government Medical College, Aurangabad(MS)

3. Professor \& Head, Department of Surgery, Government Medical College, Aurangabad(MS)

\section{CORRESPONDING AUTHOR:}

Dr. Suresh R. Harbade,

House No. 1-9-75, Near Maitree Computers.

Dr. Babasaheb Ambedkar Marathwada University Gate

Jaisingpura, Aurangabad - 431001

Maharashtra, India.

E-mail: drsharbade@gmail.com

ABSTRACT: Lymphangioma (cystic hygroma) is benign congenital malformation of the lymphatic system commonly present in the neonate or in early infancy. The cysts are generally filled with clear lymph and the commonest site is neck. We present a case of unusual giant lymphangioma of the breast in an adult female. The relevant literature is briefly revived.

KEY WORDS: Lymphangioma, cystic hygroma, breast.

INTRODUCTION: Lymphangiomas are usually discovered in infants or children less than two years of age and occurrence in adults is uncommon, and fewer than 100 cases of adult lymphangioma have been reported ${ }^{1}$. Breast lymphangioma is extremely rare lesion; a review of literature revealed only 10 cases reported until now. ${ }^{1-4}$ we report a case of large lymphangioma of breast in a young female.

\section{CASE REPORT:}

MATERIALS AND METHODS: A 23 - year - old woman presented with lump in right breast of two months duration. General and systemic examination was noncontributory. Local examination revealed a large $(20 \mathrm{~cm} \times 10 \mathrm{~cm})$ mobile, cystic, slightly tender and non-transilluminent swelling in upper outer quadrant with extension in axilla (Fig 1). There was no axillary lymphadenopathy. Breast sonography revealed large cyst with internal echo's suggesting haemorrhage with single solid nodule. Fine needle aspiration cytology was reported as inflammatory. Routine hematological and biochemical investigations were normal.

Under general anesthesia the entire lump was excised preserving vital structures of axilla (Fig 2). The cystic lesion had fibrous lining with dirty hemorrhagic fluid. The histopathological diagnosis was cystic hygroma of breast. At one year follow-up there was no recurrence.

DISCUSSION: Lymphangiomas are generally seen before the age of two years and the common sites are neck (70\%), axilla (20\%) and the remaining 10\% in the abdominal organs, the retroperitoneum, skeleton, scrotum and vary rarely the breast.

Some regard lymphangiomas to be true neoplasms capable of local aggressive behavior but overall they are benign. Others believe that they are hamartomatous malformation resulting from 
failure of lymphatic system to communicate with the venous system or they represent sequestered lymphatic tissue that fails to communicate with lymphatic system.

Lymphangiomas are classified as simple (consist of small sized capillary vessels); cavernous (composed of dilated lymphatic vessels surround by fibrous capsule) and cystic (characterized by large cyst-like spaces filled with clear lymph fluid, containing lymphocytes and erythrocytes). They are lined by endothelial cells with well-defined margins and capsule and sometimes with focal areas of papillary endothelial proliferations as seen in the present case.

A breast lymphangioma is usually a smooth asymptomatic mass called lymphangioma circumscriptum. However rapid expansion may occur due to hemorrhage and infection (as in present case) or trauma. It may be associated with chromosomal and other anatomical anomalies (c.f. present case).

Lymph vessels of the adult mammary gland originate in the interlobular connective tissue and the walls of lactiferous ducts. These communicate with the overlying cutaneous lymphatic plexus, especially around the nipple in subareolar plexus, and then drain to the axilla. The reported sites of breast cystic lymphangioma are upper outer quadrant, axillary tail of Spence and subareolar are related to the route of the lymphatic system. The sizes reported varied from three to $25 \mathrm{~cm}$ in diameter.

The differential diagnosis of cystic hygroma include simple cyst, post surgical liquid collection, haematoma, lymphocele, abscess, hemangioma, lymphangiomyomatosis and lymphangiectasis. Simple breast cysts are usually bilateral and found in patients of chronic mastitis often seen in other regions of breast. Lymphangiomyomatosis is localized to the lymphatics of mediastinum, retroperitoneum and pulmonary parenchyma and characterized by smooth muscle proliferation in the affected lymphatics. Lymphangiectasis occurs in patients who have had previous surgery and radiation therapy for malignancy. Morbidly obese individuals may develop lymphangiectasis due to the weight of large dependant folds of fat causing lymphatic obstruction.

Sonography reveals multiloculated cystic mass with septa of variable thickness that insinuates between tissue planes. However in the present case because of haemorrhage and infection ultrasound revealed large collection with internal echoes. On mammography, round or lobulated masses can be seen. In doubtful cases computed tomography and magnetic resonance imaging may be helpful. Since radiographic images are not always sufficient to make a definitive diagnosis, fine needle aspiration cytology is often performed

Sclerotherapy, incision, drainage, irradiation and cryotherapy are ineffective and surgical removal is the treatment of choice. It may be difficult to obtain safe margins due to tendency of these lesions to infiltrate surrounding tissues; there is a high risk of incomplete excision possibly leading to rapid recurrence.

RESULT: In conclusion, although breast cystic lymphangioma is exceedingly rare, it should be kept as a differential diagnosis of a cystic breast lump. The typical location at upper outer quadrant and axillary tail should be kept in mind. The imaging modalities and cytology may support the diagnosis. The purpose of breast imaging is to demonstrate anatomical extent of the lesion.

\section{REFERENCES:}




\section{CASE REPORT}

1.

Guner A, Aydin A, Celik F - Cystic hygromas in adult - reports of two cases. Bakirkoy Top Dergisi 2006; 2:101-3.

2.

Torcasio A, Veneroso S, Amabile MI, Biffini M, Martino G, Monti M, Tintisona Pasta V- Cystic hygroma of the breast : A rare lesion. Tumor 2006; 92:347-50.

3. Ogun GO, Oyetunde O, Akang E - Cavernous lymphangioma of the breast. World J Surg Oncology 2007; 5:69-73.

4. Chung SY, Oh KK, Kim DJ - Mammographic and Sonography findings of a breast cyst lymphangioma. J Ultrasound Med 2003; 22: 307-9.

Fig-1:- Pre- Operative Photograph

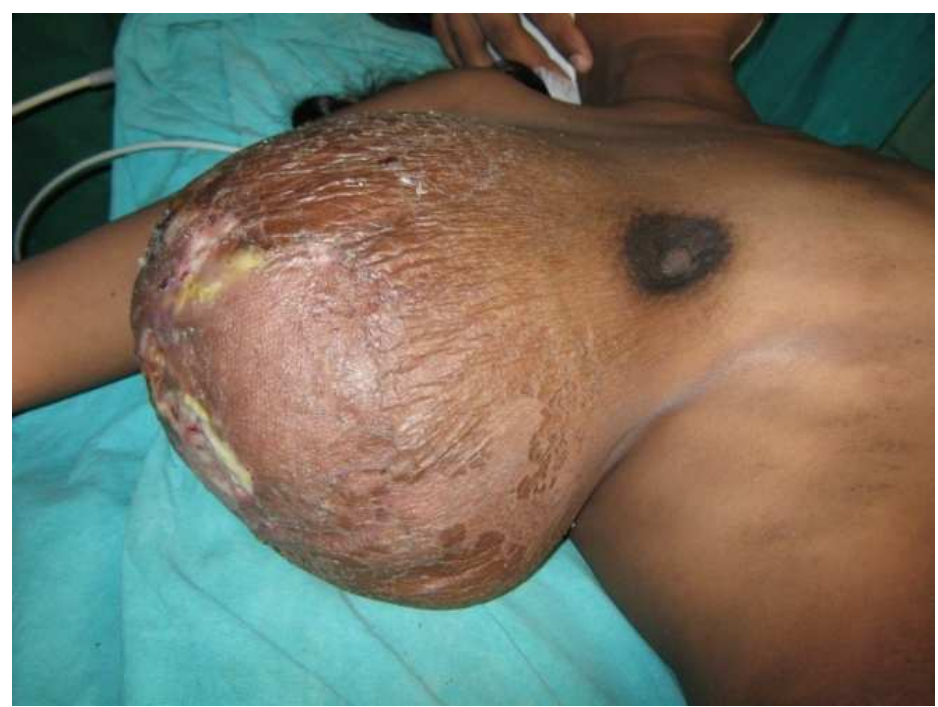

Fig-2:- Intraoperative Photograph

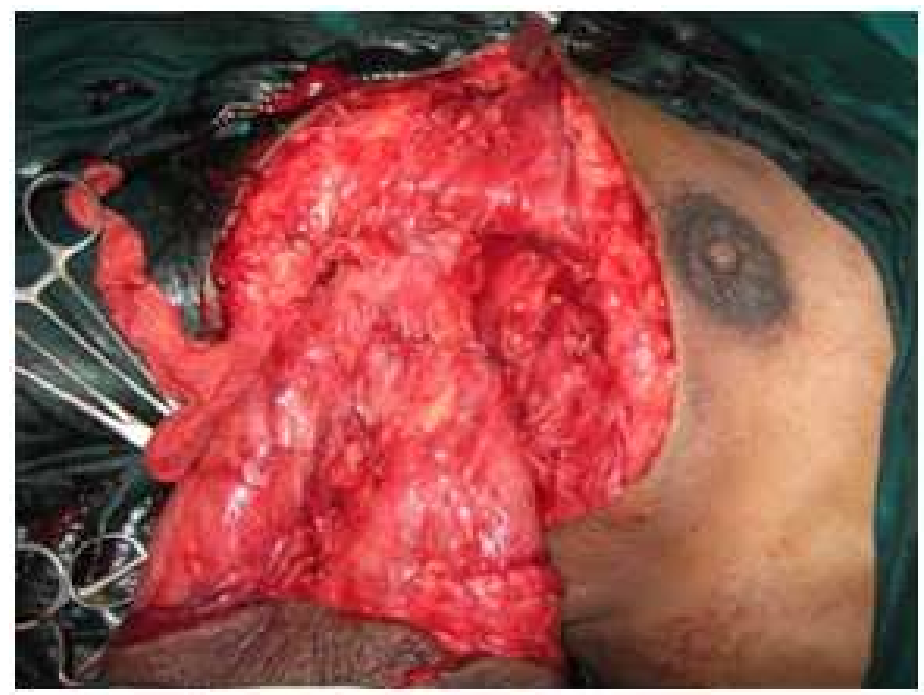




\section{CASE REPORT}

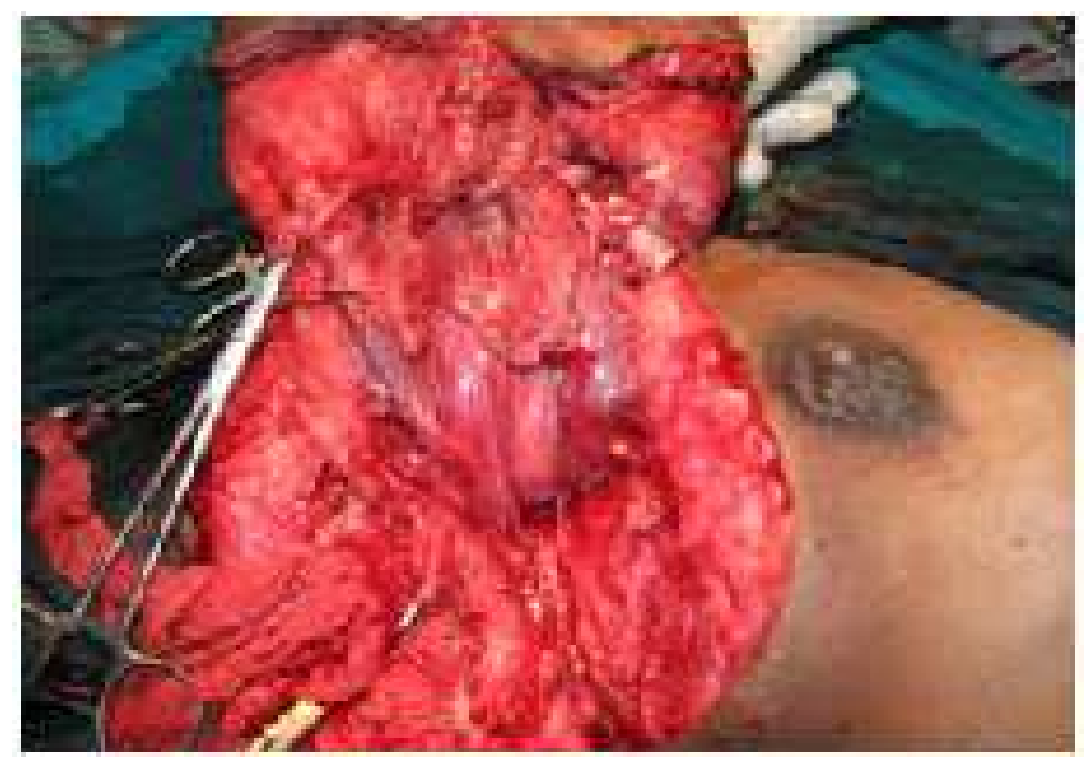

Fig-2:- Intraoperative photograph

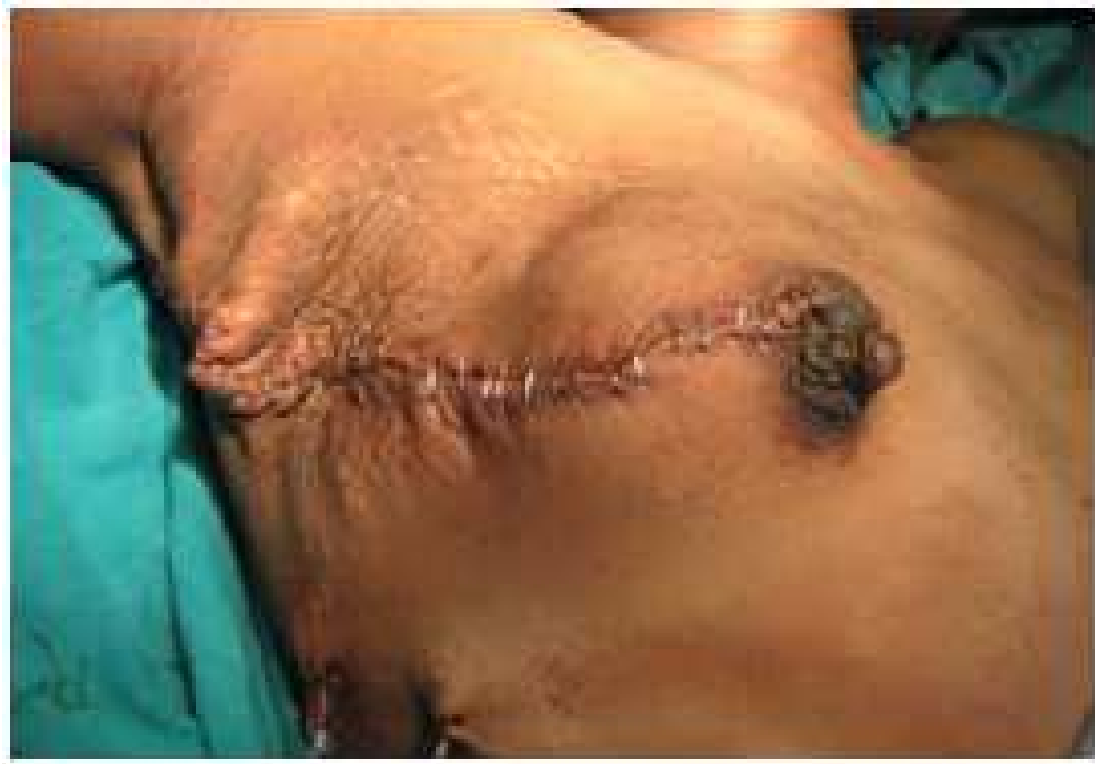

Fig-3:- Post Operative Closure Of Wound 


\section{CASE REPORT}

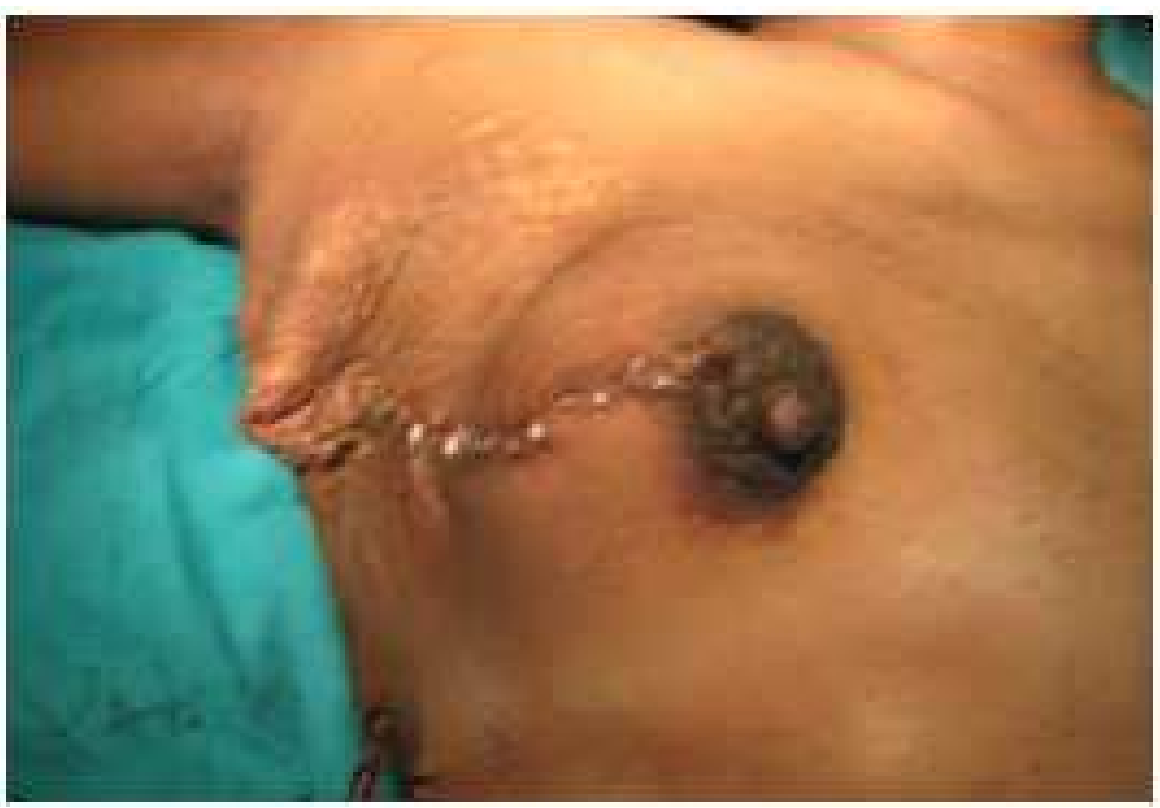

Fig-3:- Post Operative Closure Of Wound

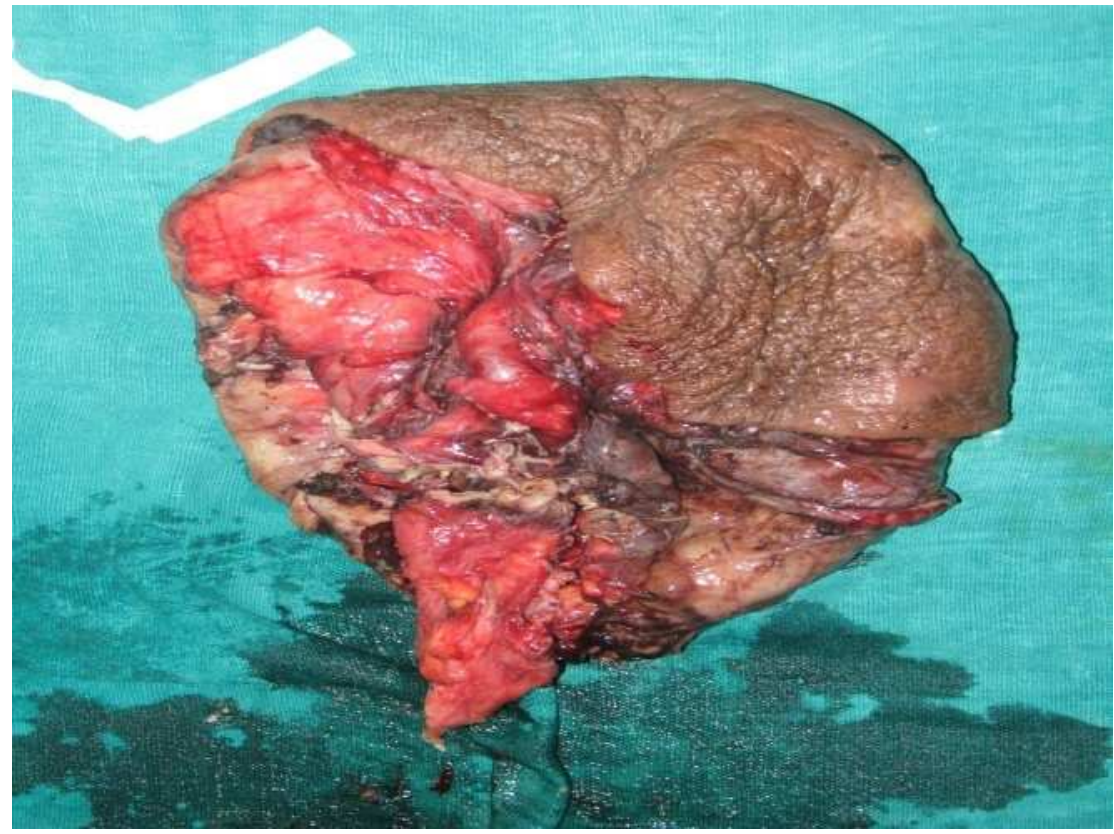

Fig-4:- post operative specimen 